\title{
Noise level analysis in adult intensive care unit
}

\author{
Análise do nível de ruído em unidade de terapia intensiva adulto
}

Helen Katharine Christofel $^{1}$, Joselene Gomes Madeiras ${ }^{1}$, Sônia Maria Marques Gomes Bertolini² ${ }^{2}$ Juliana Maria de Oliveira ${ }^{2}$

Objective: to analyze the noise level in adult intensive care unit. Methods: a quantitative study, in which the sound levels of the intensive care unit have been assessed by means of a decibel meter. Results: comparing the groups, there was a reduction in noise levels in both periods studied, but only in the afternoon there was a statistically significant difference $(p<0.05)$. The health professionals pointed out that the unit had moderate noise, coming mainly from equipment and professionals. Conclusion: adjusting the ventilator alarms contributed to the reduction of noise levels in the unit, and there was the perception that it is a moderate noise environment, although the noise levels in decibels observed were above the recommended values.

Descriptors: Noise; Intensive Care Units; Ventilators, Mechanical.

Objetivo: analisar o nível de ruído em unidade de terapia intensiva adulto. Métodos: estudo quantitativo, em que se aferiram os níveis sonoros da unidade de terapia intensiva por meio de decibelímetro. Resultados: comparando-se os grupos, verificou-se a redução dos níveis de ruído em ambos os períodos estudados, porém somente no período da tarde houve diferença estatisticamente significativa $(\mathrm{p}<0,05)$. Os profissionais apontaram que a unidade apresentava ruído moderado, oriundo principalmente dos equipamentos e profissionais. Conclusão: o ajuste dos alarmes de ventilação mecânica contribuiu para a redução dos níveis de ruído na unidade, e houve percepção de que se trata de um ambiente de ruído moderado, apesar de os níveis de ruído em decibéis observados estarem acima dos valores recomendados.

Descritores: Ruído; Unidades de Terapia Intensiva; Ventiladores Mecânicos.

\footnotetext{
${ }^{1}$ Hospital Santa Casa de Maringá. Maringá, PR, Brazil.

${ }^{2}$ Centro Universitário de Maringá. Maringá, PR, Brazil. 


\section{Introduction}

With the advent of the industrial revolution and mechanization, many noises produced by machinery and equipment became part of the workers' daily activities, and it is not from to today that the problems caused by excessive noise on human health have been discussed. In fact, the environmental noise is present in almost all urban surroundings and it is also found in hospitals, especially in intensive care units, where there is a greater concentration of diagnostic and therapeutic technologies, causing higher noise levels resulting from work and operation.

However, existing monitoring systems in intensive care units often have high sensitivity and low specificity, generating high incidence of alarms with low clinical relevance. The high number of alarms is a potential risk to health and safety of the patient in intensive care, not only by organic disorders caused by high levels of noise, as well as for leading the health professionals to a process of desensitization (reduction of alertness and confidence in the sense of urgency of these alarms), resulting in the so called "alarm fatigue"(1).

This phenomenon occurs when a large number of alarms covers up other clinically significant ones, allowing some relevant alarms to be disabled, silenced or ignored by the staff, jeopardizing the security of severely ill patient in intensive care, and the lack of response to relevant alarms can have serious consequences on the patient's clinical condition ${ }^{(2)}$.

The intensity or volume of sound is measured in units called decibel, which indicate the level of sound pressure with zero decibel up to the limit of human hearing. The sound level measured in curve A reflects the normal range of human hearing ${ }^{(3)}$.

The intensive care unit environment is stress generator for the patients, mainly due to the noise level, considered above the recommended by the Brazilian Association of Technical Standards, which provides that safe level of hospital noise should range between 35 and 45 decibels $^{(3-5)}$.
High noise levels can cause behavioral disorders, resulting in physiological responses to stress in hospitalized patients, and the intensity of the sound pressure at 65 decibels can affect the hypothalamus and the pituitary gland, increasing adrenaline secretion levels, nor epinephrine and corticosteroids, as well as causing increased blood pressure, changes in heart beat rate and peripheral vasoconstriction $^{(5-7)}$.

In professionals, the adverse effects of continuous exposure to noise also involves headache, hearing loss, confusion, low power of attention, irritability, burnout, job dissatisfaction and the professionals may be impaired in the performance of their functions ${ }^{(7-10)}$.

A quiet environment can bring numerous benefits to the reestablishment of the health of patients and reduce the stress of professionals. However, the intensity of existing noise in intensive care units is still underestimated, explaining the importance of this study, since quantifying this problem is the first step in order to suggest measures to remedy it.

Thus, this study aimed at analyzing the noise level in adult intensive care unit.

\section{Methods}

It is a quantitative study, made in intensive care unit of a hospital in a Northwestern county of Parana State, Brazil, from the $9^{\text {th }}$ to the $16^{\text {th }}$ of November 2015. It is highlighted that the intensive care unit in question uses the mechanical ventilation in the patients; the ventilator is Intermed ${ }^{\circledR}$, model i X $5^{\circledR}$.

For the study, the noise level was measured in decibels, considering the values of the curve, and adjustment of mechanical ventilation alarm was based on safe limits proposed by the model of ventilator manual i X5 $5^{(11)}$.

The seven distinct locations of the intensive care unit were chosen observing the physical distribution of beds, to cover the whole room extension and for the purposes of this study, they were designated A, B, C, D, 


\section{E, $F$ and $G$.}

The study population consisted of all the professionals who were working in that unit at the time of data collection, and the subjective evaluation of the perception of professionals about the noise the subjects were submitted to a questionnaire prepared by the authors in order to identify the intensity and the main sources of noise perceived in the unit. For the measurement of sound levels in decibels, the device Instrutherm THDL 400 was used by a Work Safety Technician.

The study was made in two stages: the first stage, the questionnaire on the perception of noise of the professionals was used and the measurement of the noise level in each of the seven locations in two different times of day, one in the morning at 8:30 am and in the afternoon at 2:30 pm, resulting in 28 decibel values. It was considered as the lowest value and the highest value in the range of twenty seconds of measurement.

The second phase occurred after seven days, during which new measurements of the noise level were made at the same times (in the morning at 8:30 am and in the afternoon at 2:30 pm) and locations of previous measurements, and after each measurement the questionnaire was reused in the professionals.

During the seven days of the study there was the daily checking and adjustments of mechanical ventilation alarms in two periods of the day, at 12:00 am and 7:00 pm, during which the alarms of the ventilators of the patients were set. The various professionals who intervene in the ventilation process could occasionally modify the setting of preset alarms, the reason why this process of checking and adjustment was used.

The questionnaire was applied to all employees present at the site, at the time of the measurements (morning and afternoon). Exclusion criteria were: illiterate, deaf subjects or having limited hearing ability, using hearing aids with cognitive and/or motor impairment that would prevent understanding and the filling of the questionnaire, or would not participate in the second test or refused to participate in the study not signing the Informed Consent Form.

The data obtained in the measurements were statistically analyzed using the BioStat $5.0^{\circledR}$ software, and data normality was verified by the Shapiro-Wilk test, and the data were statistically analyzed using the Kruskal-Wallis test and Dunn, to verify the existence of statistically significant difference between the measured noise before and after the setting of alarms, and other data were analyzed, using tables designed in Microsoft Excel $2013^{\circledR}$ software.

The study complied with the formal requirements contained in the national and international regulatory standards of research involving human beings.

\section{Results}

Initially, the study population was composed of 40 professionals from different fields (nurses, nursing technicians, physical therapists and doctors) working in the adult intensive care unit of the hospital, but in the course five professionals were excluded who did not answer the second use of the questionnaire. Of the 35 remaining professionals, 19 worked in the morning, for six hours, and 16 worked in the afternoon, also with six hours of work, with average age of $31 \pm 6$ and $29 \pm 5$ years, respectively, and the predominant gender was female, 11 in the morning and 14 in the afternoon.

Regarding noise levels obtained in the eight collection sites, in the first measurement, a minimum of 47.6 (site F) and a maximum of 65.4 decibels (site E) were found in the morning and in afternoon, the minimum value was 52.9 (site D) and a maximum of 63.7 decibels (site B). In the second measurement, the minimum in the morning was 43.2 decibels (site G) and a maximum of 68 decibels (site A), and in the afternoon, the minimum was 46.3 decibels (site $G$ ) and a maximum of 60.2 decibels (site B). As a minimum and maximum noise value in each of the sampling sites was obtained, it was possible to establish an 
average among the eight values of minimum and maximum noise in each measurement and also to make a comparison of these values (Table 1).

At the first measurement, the alarms of mechanical ventilators in points $B, E$ and $G$ in the morning and at points $\mathrm{A}$ and $\mathrm{B}$ in the afternoon, were active and during the second measurement no mechanical ventilator had active alarms, and the minimum noise level measured throughout the collection was 43.2 decibels, in the second measurement.

Regarding the differences between the measurements, only the values in the afternoon presented statistically significant difference $(\mathrm{p}<0.05)$, after adjusting the parameters of alarms, according to the ventilator manual, as recorded in Table 1.

Table 1 - Comparison of average values of noise in decibels before and after the setting of alarm

\begin{tabular}{lccc}
\hline $\begin{array}{l}\text { Decibels } \\
\text { Morning }\end{array}$ & First measurement & Second measurement & $\mathbf{p}^{*}$ \\
\hline Minimum & $55.24 \pm 4.40$ & $51.02 \pm 4.66$ & 0.0845 \\
Maximum & $60.96 \pm 4.83$ & $59.32 \pm 4.16$ & 0.2769 \\
Afternoom & & & \\
Minimum & $54.74 \pm 1.86$ & $50.40 \pm 3.21$ & 0.0297 \\
Maximum & $60.10 \pm 2.49$ & $55.18 \pm 3.20$ & 0.0127 \\
\hline Kruskal-Wallis test with Dunn post test & &
\end{tabular}

In the morning, although there was no statistically significant difference between the values in the first measurement (before setting the alarms) and the second measurement (after adjustment) it was observed that there was a small decrease in average values (Table 1).

Regarding the noise observed at the unit, in the first use of the questionnaire in the morning, most professionals (13 out of 19) considered that the intensive care unit, most of the time, had moderate noise and seven of 19 professionals said they considered that it had intense noise; in the afternoon, most ( 9 out of 16) stated that the unit had loud noise and seven said that there was same moderate noise.

However, in the second use of the questionnaire, there was change in those values, occurring reduction in the number of subjects who claimed that the unit had intense noise in both periods, from seven to five in the morning and from nine to four in the afternoon. However, the number of professionals who claimed that the unit had moderate noise increased proportionally from 11 to 13 in the morning and from seven to 12 in the afternoon. The number of subjects who claimed that the unit was quiet (one in the morning and none in the afternoon) remained unchanged.

When asked about the source of noises in the care unit, in the first use of the questionnaire in both periods, most of the answers (19 out of 35 morning and 14 out of 24, afternoon, $54.0 \%$ and $58.0 \%$, respectively) showed the equipment as originating most part of the noises.

In the second use, in the morning, there was a reduction in the number of responses that indicated the equipment as a source of noise (13 out of 33, that is $39.0 \%$ ) and an increase in the number that pointed out the professionals (18 out of 33 , corresponding to $55.0 \%$ of responses). In the afternoon, 14 out of 24 , or $58.0 \%$ of the responses in the first use, and 14 out of 22 , or $64.0 \%$ in the second, indicated the equipment as a source of increased noise, followed by professionals (38.0\% of responses, the first use, and $36.0 \%$ in the second), and professionals could point out more than one item as noise generator.

Concerning equipment that produced more alarm noises, most of the answers in both periods and uses pointed out multiparameter monitors such as those that produce more noise, and in the first use of the questionnaire 13 out of 22 answers (59.0\%) in the morning, and 12 out of 25 (48.0\%) answers in the afternoon. In the second use of the questionnaire, 13 out of 23 responses (57.0\%), in the morning, and 11 out of $23(48.0 \%)$ answers in the afternoon, followed by infusion pumps, with $23.0 \%$ of responses, in the 
morning, in the first use, and $35.0 \%$ in the afternoon and in the second use, $28.0 \%$ and $30.0 \%$, respectively.

Thus, among the professionals working in the unit, before setting the alarms, the prevailing perception was that the intensive care unit had moderate noise during the morning and intense in the afternoon, and after adjustments the was a predominant perception of moderate noise. Subjects studied judged that the noise was especially coming from equipment and professionals, who pointed out the multiparameter monitors as the equipment that had more alarm noise among the options presented (infusion pumps, mechanical ventilators and multiparameter monitors).

As for possible changes resulting from exposure to such noise levels, in the first use of the questionnaire, $89.0 \%$ of professionals in the morning and $88.0 \%$ in the afternoon reported that the noise could harm patients, and the second measurement the number of responses increased to $95.0 \%$ and $100.0 \%$, respectively.

When asked if the noise could harm the professionals themselves, in the first use of the questionnaire $68.0 \%$ of professionals in the morning and $94.0 \%$ of in the afternoon responded that the noise could harm. In the second measurement, these values changed to $79.0 \%$ and $69.0 \%$, respectively, and, in the afternoon, during which there was a reduction in the percentage of individuals who said the noise could harm the professionals, it was found that there was an increasing number of subjects who said the noise did not hurt, or no answer, but still a minority.

Regarding the effect of noise on the accompanying members in the morning, $58.0 \%$ of the professionals said that the noise in the unit could damage the accompanying members, $37.0 \%$ said that the noise would not harm and 5.0\% did not know, values that were not changed in the second use of the questionnaire.

In both periods, most professionals said that the noise could harm the accompanying members $75.0 \%$ in the first use and $44.0 \%$ in the second), although in the second use, the number of professionals who said that the noise does not harm the accompanying members increased, being $19.0 \%$ in the first use to $31.0 \%$ in the second, as well as those who were unable to respond $(6.0 \%$ in the first use and $25.0 \%$ in the second).

When asked if they observed the individual behavior as noise generator in the Intensive Care Unit, in the first use, most professionals in the mornings $(52.6 \%)$ said "no," and in the afternoon the majority $(68,7 \%)$ said "yes." In the second use, most went on to state that "yes" in both periods, and believed to be possible to mitigate these levels (Table 2).

Table 2 - Perception of the professionals about generating noise due to their behavior and about the possibility of reducing the existing noise in an intensive care unit

\begin{tabular}{lccc}
\hline \multirow{2}{*}{ Answers } & Measurements & $\begin{array}{c}\text { Does your behavior } \\
\text { generate noise? }\end{array}$ & $\begin{array}{c}\text { Is it possible to } \\
\text { reduce noise in } \\
\text { the care unit? }\end{array}$ \\
\cline { 3 - 4 } Morning & & n (\%) & n (\%) \\
Yes & First & $7(36.8)$ & $17(89.4)$ \\
No & Second & $9(47.4)$ & $18(94.7)$ \\
I don't know & First & $10(52.6)$ & $1(5.3)$ \\
Afternoon & Second & $7(36.8)$ & - \\
Yes & First & $2(10.5)$ & $1(5.3)$ \\
& & $3(15.8)$ & $1(5.3)$ \\
No & First & $11(68.7)$ & $14(87.5)$ \\
& Second & $9(55.3)$ & $14(87.5)$ \\
& First & $3(18.7)$ & - \\
& Second & $6(37.5)$ & $2(12.5)$ \\
& First & $2(12.5)$ & $2(12.5)$ \\
\hline
\end{tabular}

\section{Discussion}

Among the limitations found in the study, it was highlighted the fact that the checking of the audiometric profile of the subjects were not carried out, considering its influence on the perception of the noise level. The short period of data collection and small size of sample also imply limitations for 
statistical analysis, generalization and support for the conclusions.

However, it was found that the average noise recorded in the seven collection sites exceeded 45 decibels, and this finding suggests that the intensive care unit studied is an environment with high noise levels and agrees with the perception of most subjects of sample, who considered the environment noisy. This finding corroborates other studies in hospitals in Brazil, which also found high noise levels ${ }^{(4-5)}$.

Studies in Intensive Care Units in other countries, such as Iran ${ }^{(12)}$, United States ${ }^{(13)}$ Sweden $^{(14)}$ and the Netherlands ${ }^{(15)}$ also showed high noise levels, which indicate that the high noise level is not characteristic of the unit in question, but can be a common problem.

The results obtained in this study, both the measurement noise as the use of the questionnaires indicate that the professionals present in the unit identified high levels of noise and its origin, realized that they could negatively affect patients and workers and understood that the levels could be reduced, but still lacked strategies for this.

The participation of professionals, especially nursing staff in designing initiatives to improve noise levels as well as the management process and management of alarms in the intensive care unit, appears to be a determining factor for the solution of that condition.

This study encourages discussion about the noise in intensive care units and points to the need for greater attention to this issue, especially by managers and health professionals in order to generate an environment which favors to both the best care performance health and the recovery of patients.

In intensive care units, there are several elements that contribute to the existence of noise, elements ranging from computers, telephones, bathroom carts to the large number of equipment and technologies for the treatment and monitoring of patients, for which the presence of alarms and audible alerts are outstanding ${ }^{(5-7)}$. The professionals of the intensive care unit studied showed the equipment as important sources of noise and, in fact, after the correct adjustment of mechanical ventilation alarms, reduction was observed in the noise levels, although only in the afternoon, has there been statistically significant difference.

However, the team itself may be primarily responsible for the noise in intensive care units, but professionals are generally unaware of this fact ${ }^{(3,5,8)}$. In the present study, there was a large number of responses that indicated professionals as a major source of noise, but less than half of the professionals pointed behavior as noise generator, when asked the first time, and just over half of them in the second use of the questionnaire.

Another factor to be considered when discussing the noise in the Intensive Care Unit is the patient and his characteristics, which may vary according to the severity of the disease, the stages of treatment and recovery ${ }^{(14)}$. One cannot ignore also the noise level adjacent to the bed of the patient, and from other sources, such as alarms, equipment and the position of the bed related to the hospital plant. In this sense, the training and education of staff, the repositioning of equipment and adjustments to alarm levels appear to significantly influence in reducing noise ${ }^{(16-17)}$.

Because it is a closed environment, the acoustics of the intensive care unit is usually unfavorable, making it more susceptible to noise, such as the frequent emission of sound signals (alarms) by the various equipment necessary for the care and monitoring of critically ill patients, facilitating the identification of abnormal situations with patients ${ }^{(3,6,10)}$, however, studies that address the parameterization of alarms in care units are still scarce in the literature and this study suggests that the parameterization can contribute to reduce noise in the unit.

In addition to harming patients, high levels of noise can also negatively affect the staff, causing 
stress and may impair the ability to provide care, especially in the nursing team, which is subject to longer exposure to this problem ${ }^{(18)}$. Nevertheless, the occurrence of false alarms and the lack of recognizing the importance of those also affect the safety of care to critically ill patients ${ }^{(19)}$.

Some studies suggest that the lack of systematic measurements of noise, lack of knowledge about the sound pressure levels and even the structural aspects (such as the absence of acoustic coating) make it difficult to maintain a proactive approach, aimed at maintaining an acoustically, comfortable and safe environment ${ }^{(3,10,12)}$.

Concerning the noise effects on the sleep of the patient, measures, besides team training, may prove to be effective, such as providing hearing protection, introduction of background noise and closing doors at night or during the sleeping period ${ }^{(20)}$.

\section{Conclusion}

The findings of this study support the conclusion that the adjustment of mechanical ventilation alarms contributed to the reduction of noise levels in the intensive care unit, and that among the professionals working there, it was noticed that it is a moderate noise environment, despite the fact that the noise levels in decibels observed are above the levels recommended by the World Health Organization and the Brazilian Association of Technical Standards.

\section{Collaborations}

Christofel HK and Madeiras JG contributed to the design of the project, collecting and analyzing data, writing and critical analysis relevant content. Bertolini SMMG and Oliveira JM contributed in the writing and relevant critical analysis of content and final approval of the version to be published.

\section{References}

1. Bridi AC, Louro TQ, Silva RCL. Clinical Alarms in intensive care: implications of alarm fatigue for the safety of patients. Rev Latino-Am Enfermagem. 2014; 22(6):1034-40.

2. Bridi AC, Silva RCL, Farias CCP, Franco AS, Santos VLQ. Reaction time of a health care team to monitoring alarms in the intensive care unit: implications for the safety of seriously ill patients. Rev Bras Ter Intensiva. 2014; 26(1):28-35.

3. Stafford A, Haverland A, Bridges E. Noise in the ICU: what we know and what we can do about it. Am J Nurs. 2014; 114(5):57-63.

4. Campos JF, David HSL. Work context assessment in intensive therapy units from the perspective of work psychodynamics. Rev Esc Enferm USP. 2011; 45(2):363-8.

5. Filus WA, Pivatto LF, Fontoura FP, Koga MRV, Albizu EJ, Soares VMN, et al. Noise and its impact on Brazilian hospitals: a literature review. Rev CEFAC. 2014; 16(1):307-17.

6. Duarte ST, Matos M, Tozo TC, Toso LC, Tomiasi AA, Duarte PAD. Praticando o silêncio: intervenção educativa para a redução do ruído em Unidade de Terapia Intensiva. Rev Bras Enferm. 2012; 65(2):285-90.

7. Daniele D, Pinheiro EM, Kakehashi TY, Balieiro MMFG. Workers' knowledge and perception regarding noise in the neonatal unit. Rev Esc Enferm USP. 2012; 46(5):1041-8.

8. Weich TM, Ourique AC, Tochetto TM, Franceschi CM. Eficácia de um programa para redução de ruído em unidade de terapia intensiva neonatal. Rev Bras Ter Intensiva. 2011; 23(3):327-34.

9. Araújo LM, Germano RM, Valença CN, Moura KS, Araújo LM. The experience of nurses in intensive care: phenomenological study. Rev Rene. 2011; 1(2):316-23.

10. Santana LSR, Silva LS, Silva RR, Carvalho JE, Santana WS, Rossi-Barbosa LAR, et al. Measurement of acoustic noise levels in a neonatal intensive care unit. Rev Min Enferm. 2015; 19(2):27-31. 
11. Intermed Equipamento Médico Hospitalar Ltda. Manual de Operação X5 ventilador pulmonar: manual de operação código 806.00474 - Revisão 002. São Paulo: Intermed; 2011.

12. Abbasi S, Talakoob R, Soltani F, Yousefi $H$. Evaluating the noise level and sources in Isfahan University Hospital's Intensive Care Units. J Isfahan Med Sch. 2011; 28(118):1-8.

13. Zhe W, Downs B, Farell A, Cook K, Hourihan P, McCreery S. Role of a service corridor in ICU noise control, staff stress, and staff satisfaction: environmental research of an Academic Medical Center. HERD. 2013; 6(3):80-94.

14. Park M, Vos P, Vlaskamp B, Kohlrausch A, Oldenbeuving A. The influence of APACHE II score on the average noise level in an intensive care unit: an observational study. BMC Anesthesiol [Internet]. 2015 [cited 2016 Mar 13]; 15:42. Available from: http://bmcanesthesiol.biomedcentral.com/ articles/10.1186/s12871-015-0019-7

15. Tegnestedt C, Günther A, Reichard A, Bjurström R, Alvarsson J, Sackey P, et al. Levels and sources of sound in the intensive care unit - an observational study of three room types. Acta Anaesthesiol Scand. 2013; 57(8):1041-50.
16. Darbyshire J, Young J. An investigation of sound levels on intensive care units with reference to the WHO guidelines. Crit Care [Internet]. 2013 [cited 2016 Mar 13]; 17(5):187. Available from: http:// ccforum.biomedcentral.com/articles/10.1186/ cc12870

17. Konkani A, Oakley B, Penprase B. Reducing hospital ICU noise: a behavior-based approach. J Healthc Eng. 2014; 5(2):229-46.

18. Mahmood A, Chaudhury H, Valente M. Nurses' perceptions of how physical environment affects medication errors in acute care settings. Appl Nurs Res. 2011; 24(4):229-37.

19. Sowan AK, Tarriela AF, Gomez TM, Reed CC, Rapp KM. Nurses' Perceptions and practices toward clinical alarms in a transplant cardiac Intensive Care Unit: exploring key issues leading to alarm fatigue. JMIR Hum Factors [Internet]. 2015 [cited 2016 Mar 13]; 2(1):3. Available from: http://www. ncbi.nlm.nih.gov/pmc/articles/PMC4797660/ pdf/humanfactors_v2i1e3.pdf

20. Nannapaneni S, Ramar K, Morgenthaler T, Elmer J, Lee S. Sleep fragmentation and deprivation in critically ill patients - Is noise a factor? Sleep Med [Internet]. 2013 [cited 2016 Mar 13]; 14:e217-18. Available from: http://www.sleep-journal.com/ article/S1389-9457(13)01735-8/pdf 